\title{
Association of preoperative non-HLA antibodies with kidney allograft rejection
}

\author{
Inseong $\mathrm{Oh}^{1}$, Sehoon Park ${ }^{2}$, Kiwook Jung ${ }^{1}$, Hajeong Lee ${ }^{3}$, Eun Young Song ${ }^{1}$ \\ ${ }^{1}$ Department of Laboratory Medicine, Seoul National University Hospital, Seoul, Korea \\ ${ }^{2}$ Department of Internal Medicine, Korean Armed Forces Capital Hospital, Seongnam, Korea \\ ${ }^{3}$ Department of Internal Medicine, Seoul National University Hospital, Seoul, Korea
}

Background: Non-human leukocyte antigen (HLA) antibodies are thought to have an impact on kidney allograft rejection. We analyzed the titers of non-HLA antibodies in kidney transplant recipients at the time of transplantation and screened which antibodies are associated with kidney allograft rejection.

Methods: The study included 400 preoperative sera from kidney transplant recipients with biopsy-proven antibody-mediated rejection (ABMR, $n=47)$, T-cell mediated rejection $(T C M R, n=200)$, and controls without rejection $(n=153)$ at Seoul National University Hospital between 2015 and 2021. A total of 41 types of non-HLA antibodies were analyzed by Luminex method (Labscreen Autoantibody and Labscreen Mixed, One Lambda, USA) and enzyme immunoassay (EIA-AT1RX, One Lambda, USA). In multivariable logistic regression analysis, the effect of DSA and HLA mismatch are adjusted.

Results: In multivariable analysis, occurrence of ABMR was related to the increase of anti-collagen type I ( $\geq 75$ percentile value provided by the manufacturer, odds ratio [OR], 10.6; $\mathrm{P}=0.001)$ and the increase of anti-collagen type IV antibody (OR, 2.3; $\mathrm{P}=0.033)$. The occurrence of $A B M R$ was decreased with the increase of anti-ARHGDIB (OR, $0.4 ; P=0.007)$, anti-collagen II (OR, 0.3; $P=0.001)$ and anti-LG3 (OR, 0.3; $P=0.015)$. Meanwhile, the occurrence of TCMR was associated with the increase of anti-collagen II antibody (OR, 2.1; $\mathrm{P}=0.007)$.

Conclusions: The increase of anti-collagen type I and type IV antibody titers at the time of transplantation was related to ABMR of kidney allografts. The increase of anti-ARHGDIB, anti-collagen II, and anti-LG3 antibody titers was related to the decreased occurrence of ABMR. Anti-collagen II antibody was related to the occurrence of TCMR. Further researches are needed on the mechanism by which each antibody acts in the rejection of kidney allografts.

Corresponding author: Eun Young Song

E-mail: eysong1@snu.ac.kr

(c) The Korean Society for Transplantation

This is an Open Access article distributed under the terms of the Creative Commons Attribution Non-Commercial License (http://creativecommons.org/licenses/by-nc/4.0/) which permits unrestricted non-commercial use, distribution, and reproduction in any medium, provided the original work is properly cited. 